\title{
Interactive Thermal Effects on Metal-Organic Framework Polymer
}

\section{Composite Membranes}

\author{
Fernando Cacho-Bailo ${ }^{[a]}$, Carlos Téllez ${ }^{[a]}$ and Joaquín Coronas ${ }^{\star[a]}$
}

\begin{abstract}
Polymeric membranes are important tools for intensifying separation processes in chemical industries concerning strategic tasks such as $\mathrm{CO}_{2}$ sequestration, $\mathrm{H}_{2}$ production and water supply and disposal. Mixed-matrix and supported membranes have been widely developed, recently many of them based on metal-organic frameworks (MOF). However, most of MOF impacts within the polymer matrix have yet to be determined. In this work, the effects related to thermal behavior arising from the combination of MOF ZIF8 and polysulfone are quantified. The catalyzed oxidation of the polymer is strongly affected by the MOF crystal size and distribution inside the membrane.
\end{abstract}

Because of their cheap availability and shaping, polymerbased membranes are nowadays used extensively at industrial scale for crucial processes such as reverse osmosis, nanofiltration, purification of effluent streams and gas separation. ${ }^{[1]}$ Every new membrane technology deployed advances into the energy effectiveness and the intensification of chemical processes. For this reason the environmentally friendly membrane technologies are considered a real solution to stop climate change: in situ $\mathrm{CO}_{2}$ sequestration and purification of $\mathrm{H}_{2}$ for its application as an emission-free fuel are two examples of feasible membrane-based processes. ${ }^{[1 \mathrm{~b}, 2]}$

One strategy receiving considerable attention for improving the fluxes and selectivities of membranes and making them more economically attractive is the addition of nanodesigned materials as membrane fillers. ${ }^{[3]}$ MOFs (metal-organic frameworks) and specifically ZIFs (zeolitic imidazolate frameworks, a subclass of highly thermally and chemically stable MOFs) play a key role in this context. ${ }^{[c, 1 d, 4]}$ Their organic moieties and intrinsic flexibility ensure compatibility and bonding with the polymeric membrane, while their regularly sized and tunable micro- or mesoporosities help to attain a selective and efficient separation. ${ }^{[5]}$ However, there are many other issues arising from the addition of MOFs as fillers of a polymer matrix that have yet to be studied in depth, e.g. loss of thermal stability and changes in the mechanical properties of the polymer such as rigidification. ${ }^{[3 c, 6]}$ These effects may involve significant costs for membrane manufacturers.

This work examines changes in the thermal stability of composites containing prototypical materials for gas separation membranes: ZIF-8 and polysulfone (PSf), a widely used sulfurcontaining thermoplastic. ${ }^{[2 a, 7]}$ For this purpose, these composites were submitted to temperatures far above the usual working conditions (even above the glass transition temperature of the

[a] F. Cacho-Bailo, Dr. C. Téllez and Prof. Dr. J. Coronas Chemical and Environmental Engineering Department and Institute of Nanoscience of Aragón (INA)

University of Zaragoza

María de Luna, 50018, Zaragoza (Spain)

E-mail:coronas@unizar.es

Supporting information for this article is given via a link at the end of the document.
PSf) to evaluate the alterations in the thermal stability which were correlated with the nature of the corresponding composite.

ZIFs (including ZIF-8) were first dispersed and mixed within the polymer solution to produce the so-called mixed-matrix membranes (MMMs) ${ }^{[8]}$ Recently, hollow fiber (HF) polymericsupported MOF membranes have appeared, taking advantage of their valuable shapes. ${ }^{[9]}$ Both MMMs and HF-supported MOFpolymer composite membranes are intended to solve important future challenges in strategic fields such as water supply, wastewater treatment and gas separation. ${ }^{[10]}$ Nevertheless, most of the effects deriving from the addition of a ZIF to a polymer have yet to be determined.
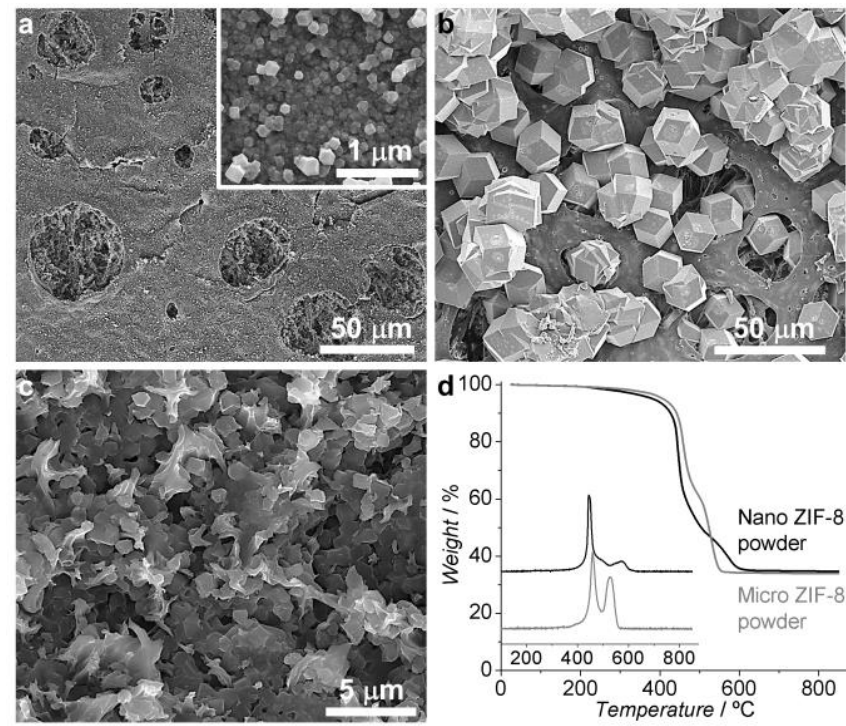

Figure 1. Scanning electronic microscopy (SEM) images of composite ZIF$8 @ P S f$ materials containing nanosized (a) and microsized (b) MOF crystals on an asymmetric highly porous flat polysulfone support. Cross-section image of 48 wt\% ZIF-8 MMM, MMM48@PSf (c). TG curves of the micro- and nanosized ZIF-8 powders, oxidized in air atmosphere at a $10^{\circ} \mathrm{C} \cdot \mathrm{min}^{-1}$ rate; inset shows the DTG curves (d).

Figure 1 shows the synthesized ZIF-8-containing composite materials. Depending on the ligand to metal ratio in the solution media, micro- or nanosized MOF crystals were supported on porous PSf supports. ${ }^{[7]}$ It can be observed that while $28 \pm 2 \mu \mathrm{m}$ micrometer-sized crystals were stuck on the polymer surface and grown inside the pores, not all the surface was completely covered. Nevertheless, $140 \pm 20 \mathrm{~nm}$ nanosized ZIF-8 completely coated the polymer surface. This nanosized ZIF-8 was also used as powder to fabricate 16 and 48 wt\% MMMs with PSf. Figure $\mathrm{S} 1$ shows XRD spectra of the fabricated materials. Thermogravimetric (TG) curves of these composite materials from 25 to $750{ }^{\circ} \mathrm{C}$ at a heating rate of $10^{\circ} \mathrm{C} \cdot \mathrm{min}^{-1}$ in an air atmosphere were obtained, together with those of the pristine PSf supports, porous and dense, and the ZIF-8 powders. It is clearly observed that, in the presence of ZIF-8, the two stages in 
the porous PSf degradation took place at much lower temperatures (Figure 2 and Table 1). The maximum weight loss rate in the former thermal decomposition occurred in the Microand NanoZIF-8@PSf materials, respectively, at temperatures ( $\left.\mathrm{T}_{\max }\right) 60$ and $57^{\circ} \mathrm{C}$ below that corresponding to the pure porous PSf $(526 \stackrel{\circ}{\circ})$. Similarly, the latter oxidation step (related with the combustion of aromatic carbon and residues from thermal decomposition) took place at temperatures 72 and $80 \stackrel{\circ}{\circ}$ below that corresponding to the raw polymer $\left(625^{\circ} \mathrm{C}\right)$ in the two above mentioned composite materials, both being completely degraded before reaching $600{ }^{\circ} \mathrm{C}$. In the case of the MMMs (16 and 48 wt\% ZIF-8 loaded) the same trend was observed: the temperatures of the weight loss rate maxima were reduced 56 and $96{ }^{\circ} \mathrm{C}$ in the MMM48@PSf curve. TG analyses in an inert atmosphere, where ZIF-8 degrades at higher temperatures than PSf, showed similar effects. Therefore $\mathrm{Zn}$ particles catalyzed the polymer degradation both being part of the crystalline ZIF-8 and as $\mathrm{ZnO}$ (Figures S2 to S4 and Table S1). Finally, $\mathrm{T}_{\max }$ values in Table 1 are far above the regular operating temperatures for this kind of membranes, in this case always below the corresponding glass transition temperature of PSf $(189 \stackrel{\circ}{\circ}) .{ }^{[3 a]}$
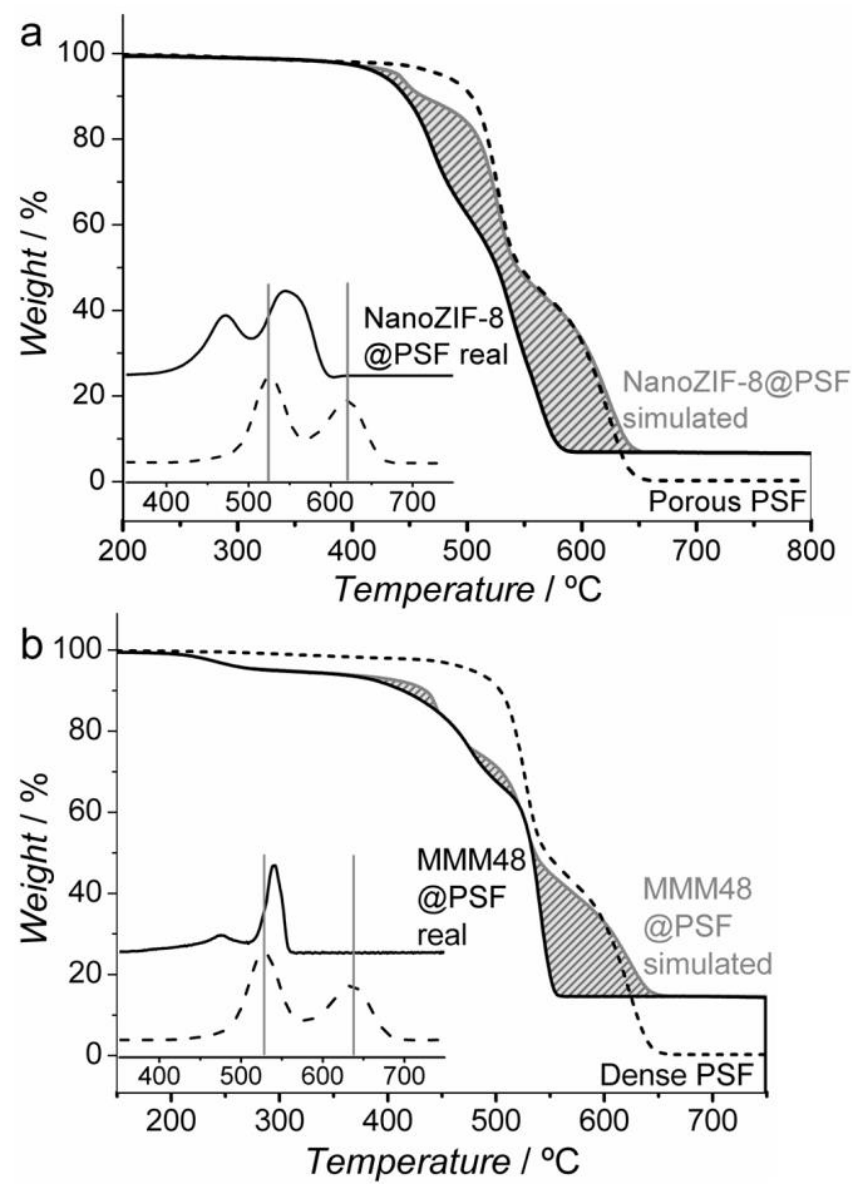

Figure 2. TG curves of the supported NanoZIF-8@PSf (a) and the $48 w t \%$ ZIF-8 MMM (b) composite materials (solid black) compared with the pristine PSf (dashed black, porous and dense, respectively) when oxidized in air atmosphere at $10^{\circ} \mathrm{C} \cdot \mathrm{min}^{-1}$. Grey curves show the simulated TG curves (powder/polymer linear combination) when no interactive effect is considered. MOF loading was obtained from residue at $750 \stackrel{\circ}{ } \mathrm{C}$ considered as $\mathrm{ZnO}$. Insets show the weight loss rate with the temperature. Degradation steps occurred at lower temperatures than expected in the composite materials due to the catalytic effect of the metallic part of the ZIF-8 (striped areas), the influence of ZIF-8 in a porous support being much more effective (see also Figure S13).

This significant loss in the thermal stability of the polymer support and therefore in the membrane (see striped areas in Figure 2) was related with the catalytic effect of the $\mathrm{Zn}$ metal particles from the MOF, ${ }^{[11]}$ already as $\mathrm{ZnO}$ because $\mathrm{ZIF}-8$ degrades at lower temperatures, as shown below. Consequently, the composite membranes reduced their thermal stability. This phenomenon could be even stronger with other MOFs containing more catalytically active metals, such as Co-based ZIF-9 or ZIF-67. ${ }^{[12]}$

$\mathrm{Zn}$ catalyzed both the thermal decomposition and the oxidation stages of the polymer, whose apparent activation energies $\left(E_{a}\right)$ clearly diminished. These energies were calculated by a differential method, based on the conversion extent, ${ }^{[13]}$ and the integral adjustments developed by Kissinger and Ozawa. ${ }^{[14]}$ All the TG analyses at four different heating rates $\left(2,5,10\right.$ and $20 \stackrel{\circ}{\circ} \cdot \mathrm{min}^{-1}$, Figures S5 to S14) and the equations applied are shown in the Supporting Information. Table 1 shows the $E_{a}$ values of the two degradation steps in the pure PSf and the composite fabricated materials, calculated by the conversion differential method. Significant reductions were observed in the energies both in the thermal decomposition and the oxidation (being as high as $56 \%$ for the porous polymer decomposition in the presence of microsized ZIF- 8 and $-53 \%$ in the case of the MMMs). This is the first time the catalytic effect of the metal clusters of a MOF on the degradation of a composite membrane causing the previously discussed loss of thermal stability has been quantified. Integral methods led to similar conclusions (Table S2).

Table 1. Pure PSf and MOF-composite material properties.

\begin{tabular}{lllll}
\hline & $\begin{array}{l}\text { ZIF-8 content } \\
{[\mathrm{wt} \%]^{[a]}}\end{array}$ & $\begin{array}{l}\mathrm{T}_{\max } \\
{\left[{ }^{\circ} \mathrm{C}\right]^{[\mathrm{b}]}}\end{array}$ & $\begin{array}{l}\Delta \mathrm{T}_{\max } \\
{\left[{ }^{\circ} \mathrm{C}\right]}\end{array}$ & $\begin{array}{l}\mathrm{E}_{\mathrm{a}}{ }^{[\mathrm{c}]} \\
{\left[\mathrm{kJ} \cdot \mathrm{mol}^{-1}\right]}\end{array}$ \\
\hline $\begin{array}{l}\text { Porous PSf } \\
\text { support }\end{array}$ & 0 & 526 & - & 285 \\
& & 625 & - & 129 \\
MicroZIF-8@PSf & 48.4 & 466 & -60 & 126 \\
& & 553 & -72 & 123 \\
NanoZIF-8@PSf & 16.3 & 469 & -57 & 154 \\
& & 545 & -80 & 79 \\
$\begin{array}{l}\text { Dense PSf } \\
\text { membrane }\end{array}$ & 0 & 531 & - & 272 \\
MMM16@PSf & 11.4 & 638 & - & 99 \\
$\begin{array}{l}\text { (140 nm ZIF-8) } \\
\text { MMM48@PSf }\end{array}$ & & 518 & -13 & 231 \\
(140 nm ZIF-8) & 43.3 & 590 & -48 & 105 \\
\hline
\end{tabular}

[a] Calculated from the averaged residue at $750{ }^{\circ} \mathrm{C}$ considered as $\mathrm{ZnO}$. [b] Maximum weight loss rate temperature of each step (i.e. thermal decomposition and oxidation) extracted from the DTG curves at 10 ${ }^{\circ} \mathrm{C} \cdot \mathrm{min}^{-1}$. [c] Apparent activation energies of each reaction step calculated by the conversion differential method from analyses at four 
Considering the residues in the TG analyses to be zinc oxide ( $\mathrm{ZnO})$, the ZIF-8 contents were calculated in all the composite materials. A significant dependence of the size \& distribution of the MOF loading on the thermal stability was deduced, since an almost 3-times lower nanosized ZIF-8 loading (16.3 wt\% in the NanoZIF-8@PSf) caused a similar loss of thermal stability as in the highly MOF-loaded composite materials (MMM48@PSf and MicroZIF-8@PSf, mixed matrix and supported membranes, respectively). Table 2 shows how nanosized ZIF-8 degraded at a slightly lower temperature (maximum weight loss rate at 444 ${ }^{\circ} \mathrm{C}$ versus $458{ }^{\circ} \mathrm{C}$ for the microsized $\mathrm{ZIF}-8$ ) and led to $\mathrm{ZnO}$ residue particles of $74 \pm 9 \mathrm{~nm}$ on average (Figure S15). NanoMOF crystals in situ grown on a porous PSf support completely coated the polymer surface and the inner porosity, thus providing more accessible metallic active sites and therefore a more efficient catalytic degradation of the polymer as compared with the microsized ZIF-8 (48.4 wt\% but not completely covering the polymer surface, with $201 \pm 23 \mathrm{~nm}$ sized $\mathrm{ZnO}$ residue particles). Nanosized ZIF-8 continues to degrade until around $600{ }^{\circ} \mathrm{C}$, displaying a strong dependence of the weight loss curves on the crystal size. ${ }^{[15]}$ In any event, the highest degradation temperature decrease $\left(-96{ }^{\circ} \mathrm{C}\right)$ ) and the lowest apparent activation energy $\left(68 \mathrm{~kJ} \cdot \mathrm{mol}^{-1}\right)$ were both observed in the oxidation step of the MMM48@PSf MMM containing a 43.3 wt $\%$ filler load and a homogeneous distribution, as shown in Table 1.

Table 2. ZIF-8 pure powder properties.

\begin{tabular}{|c|c|c|c|c|c|}
\hline & $\begin{array}{l}\text { Crystal } \\
\text { size }^{[\mathrm{a}]} \\
{[\mu \mathrm{m}]}\end{array}$ & $\begin{array}{l}\mathrm{ZnO} \\
\text { residue }^{[\mathrm{a}]} \\
{[\mathrm{nm}]}\end{array}$ & $\begin{array}{l}\mathrm{T}_{\max } \\
{\left[{ }^{\circ} \mathrm{C}\right]} \\
\text { at } 5 \\
{ }^{\circ} \mathrm{C} \cdot \mathrm{min}^{-1}\end{array}$ & $\begin{array}{l}\mathrm{T}_{\max } \\
{\left[{ }^{\circ} \mathrm{C}\right]} \\
\text { at } 10 \\
{ }^{\circ} \mathrm{C} \cdot \mathrm{min}^{-1}\end{array}$ & $\begin{array}{l}\mathrm{E}_{\mathrm{a}}{ }^{[\mathrm{b}]} \\
{\left[\mathrm{kJ} \cdot \mathrm{mol}^{-1}\right]}\end{array}$ \\
\hline MicroZIF-8 & $\begin{array}{l}28 \\
\pm 2\end{array}$ & $\begin{array}{l}201 \\
\pm 23\end{array}$ & 439 & 458 & 143 \\
\hline NanoZIF-8 & $\begin{array}{l}0.14 \\
\pm 0.02\end{array}$ & $\begin{array}{l}74 \\
\pm 9\end{array}$ & 424 & 444 & 208 \\
\hline
\end{tabular}

[a] Averaged from SEM images (Figures 1 and S15). [b] Apparent activation energy of the ZIF-8 degradation calculated by the conversion differential method from analyses at four different heating rates (Figures S16 to S18).

Finally, some effect on the ZIF-8 stability when embedded inside the PSf support can be deduced, since the apparent activation energy for nanosized ZIF-8 pure powder $\left(208 \mathrm{~kJ} \cdot \mathrm{mol}^{-1}\right.$, Table 2) was higher than that observed during the thermal decomposition stages of the composite materials $\left(154 \mathrm{~kJ} \cdot \mathrm{mol}^{-1}\right.$ in NanoZIF-8@PSf and 129 kJ.mol ${ }^{-1}$ in MMM48@PSf). These $E_{a}$ decreases were related to a delayed and therefore a faster degradation reaction of the ZIF-8 when forming a composite membrane, being higher in the case of the MMM, as expected. MOF and polymer decomposition took place in an indistinguishable stage in the composite materials at maximum weight loss rate temperatures $\left(T_{\max }\right)$ of 469 and $475{ }^{\circ} \mathrm{C}$ for NanoZIF-8@PSf and MMM48@PSf (Table 1), respectively, while the pure powder degraded at $444{ }^{\circ} \mathrm{C}$. The polymeric matrix would then act as a shell that protects the MOF particles in the membrane, also indicating a good interaction and compatibility between them.

In summary, the size and distribution of the MOF material (both as filler and coating the surface) were found to be directly related to the thermal stability loss of the resulting composite polymeric membranes. In the system studied herein, $\mathrm{Zn}$ metal clusters contained in the ZIF-8 acted as catalysts in the two-step polymer (PSf) degradation, which took place at much lower temperatures than in the pristine polymer. An important decrease was observed in the apparent activation energies calculated by three different methods from TG curves taken at different heating rates. Nanosized ZIF crystals forming a surface layer were more catalytically effective than microsized crystals, and when acting as fillers in a MMM.

The interactive filler-matrix effect on the thermal stability was analyzed and quantified from TG data from both mixed-matrix and supported membranes. Interaction in both ways was observed: besides the influence of MOF on the PSf, some protective effect of the PSf on the ZIF-8 degradation was also detected. This study deepens our understanding of the composite membranes in which the addition of fillers (including MOFs) is becoming widespread. The consequences of the addition of these next-generation materials may involve important limitations or negative restrictions on usability for the industrial application of these membranes, such as the loss of thermal stability studied here.

\section{Acknowledgements}

Financial support (MAT2013-40556-R) from the Spanish MINECO, the Aragón Government (DGA) and the European Social Fund is gratefully acknowledged. We also acknowledge the use of the Servicio General de Apoyo a la Investigación-SAI (Universidad de Zaragoza). F. C.-B. thanks the DGA for fellowship. All the microscopy work was done in the Laboratorio de Microscopías Avanzadas at the Instituto de Nanociencia de Aragón (LMA-INA). The authors acknowledge the LMA-INA for offering access to their instruments and expertise.

Keywords: metal-organic frameworks (MOFs) • polymers • membranes $\bullet$ thermogravimetry $\bullet$ thermal stability

[1] a) R. W. Baker, Ind. Eng. Chem. Res. 2002, 41, 1393-1411; b) P. Li, Z Wang, Z. Qiao, Y. Liu, X. Cao, W. Li, J. Wang, S. Wang, J. Membr. Sci. 2015, 495, 130-168; c) S. Sorribas, P. Gorgojo, C. Tellez, J. Coronas, A. G. Livingston, J. Am. Chem. Soc. 2013, 135, 15201-15208; d) L. Wang, M. Fang, J. Liu, J. He, J. Li, J. Lei, ACS Appl. Mater. Interfaces 2015, 7, 24082-24093.

[2] a) Y. Yampolskii, Macromolecules 2012, 45, 3298-3311; b) N. W. Ockwig, T. M. Nenoff, Chem. Rev. 2007, 107, 4078-4110; c) R. P. Lively, M. E. Dose, L. Xu, J. T. Vaughn, J. R. Johnson, J. A. Thompson K. Zhang, M. E. Lydon, J. S. Lee, L. Liu, Z. Hu, O. Karvan, M. J. Realff, W. J. Koros, J. Membr. Sci. 2012, 423-424, 302-313. 
[3] a) S. Qiu, M. Xue, G. Zhu, Chem. Soc. Rev. 2014, 43, 6116-6140; b) B. Zornoza, B. Seoane, J. M. Zamaro, C. Téllez, J. Coronas ChemPhysChem 2011, 12, 2781-2785; c) C. H. Lau, P. T. Nguyen, M. R. Hill, A. W. Thornton, K. Konstas, C. M. Doherty, R. J. Mulder, L. Bourgeois, A. C. Y. Liu, D. J. Sprouster, J. P. Sullivan, T. J. Bastow, A. J. Hill, D. L. Gin, R. D. Noble, Angew. Chem. Int. Ed. 2014, 53, 5322 5326; Angew. Chem. 2014, 126, 5426-5430.

[4] a) A. W. Thornton, D. Dubbeldam, M. S. Liu, B. P. Ladewig, A. J. Hill, M. R. Hill, Energy Environ. Sci. 2012, 5, 7637-7646; b) T. Yang, G. M. Shi, T. S. Chung, Adv. Energy Mater. 2012, 2, 1358-1367; c) B. Zornoza, A Martinez-Joaristi, P. Serra-Crespo, C. Tellez, J. Coronas, J. Gascon, F. Kapteijn, Chem. Commun. 2011, 47, 9522-9524.

[5] a) B. Chen, Z. Yang, Y. Zhu, Y. Xia, J. Mater. Chem. A 2014, 2, 16811 16831; b) J. Yao, H. Wang, Chem. Soc. Rev. 2014, 43, 4470-4493; c) W. Morris, C. J. Doonan, H. Furukawa, R. Banerjee, O. M. Yaghi, J. Am. Chem. Soc. 2008, 130, 12626-12627.

[6] a) S. Shahid, K. Nijmeijer, J. Membr. Sci. 2014, 470, 166-177; b) B. Seoane, C. Téllez, J. Coronas, C. Staudt, Sep. Purif. Technol. 2013 $111,72-81$; c) X. Y. Chen, H. Vinh-Thang, D. Rodrigue, S. Kaliaguine, Ind. Eng. Chem. Res. 2012, 51, 6895-6906.

[7] F. Cacho-Bailo, B. Seoane, C. Téllez, J. Coronas, J. Membr. Sci. 2014, 464, 119-126.

[8] a) B. Zornoza, C. Tellez, J. Coronas, J. Gascon, F. Kapteijn, Microporous Mesoporous Mater. 2013, 166, 67-78; b) M. S. Denny, S. M. Cohen, Angew. Chem. Int. Ed. 2015, 54, 9029-9032; Angew. Chem. 2015, 127, 9157-9160.
[9] a) B. P. Biswal, A. Bhaskar, R. Banerjee, U. K. Kharul, Nanoscale 2015 7, 7291-7298; b) A. J. Brown, N. A. Brunelli, K. Eum, F. Rashidi, J. R Johnson, W. J. Koros, C. W. Jones, S. Nair, Science 2014, 345, 72-75; c) F. Cacho-Bailo, G. Caro, M. Etxeberria, O. Karvan, C. Tellez, J. Coronas, Chem. Commun. 2015, 51, 11283-11285.

[10] C. Zhang, W. J. Koros, J. Phys. Chem. Lett. 2015, 6, 3841-3849.

[11] a) R. Jin, Z. Bian, J. Li, M. Ding, L. Gao, Dalton Trans. 2013, 42, 3936 3940; b) U. P. N. Tran, K. K. A. Le, N. T. S. Phan, ACS Catalysis 2011 1, 120-127.

[12] a) J. Yang, F. Zhang, H. Lu, X. Hong, H. Jiang, Y. Wu, Y. Li, Angew. Chem. Int. Ed. 2015, 54, 10889-10893; Angew. Chem. 2015, 127 11039-11043; b) B. You, N. Jiang, M. Sheng, S. Gul, J. Yano, Y. Sun Chem. Mater. 2015, 27, 7636-7642; c) B. Murillo, B. Zornoza, O. De La Iglesia, C. Téllez, J. Coronas, J. Catal. 2016, 334, 60-67.

[13] a) J. H. Flynn, L. A. Wall, J. Polym. Sci. B Polym. Lett. 1966, 4, 323 328; b) H. L. Friedman, J. Macromol. Sci. A 1967, 1, 57-79; c) H. L. Friedman, J. Polym. Sci. C Polym. Symp. 1964, 6, 183-195.

[14] a) R. Svoboda, J. Málek, J. Therm. Anal. Calorim. 2014, 115, 19611967; b) T. Ozawa, Thermochim. Acta 2000, 355, 35-42; c) T. Ozawa, J. Therm. Anal. 1970, 2, 301-324; d) H. E. Kissinger, Anal. Chem. 1957, 29, 1702-1706.

[15] A. Schejn, L. Balan, V. Falk, L. Aranda, G. Medjahdi, R. Schneider, CrystEngComm 2014, 16, 4493-4500. 


\section{COMMUNICATION}

Important side effects arise from the addition of fillers to polymers and might affect the rapid development of new ecofriendly membrane technologies. Fillers were originally intended to improve polymer properties, but the presence of a metal-organic framework containing zinc metal particles in polysulfone decreases its thermal stability. Filler size and distribution dependence on the kinetic parameters have been measured.

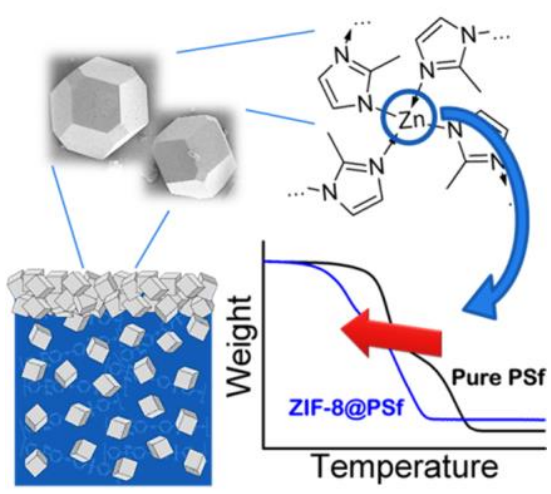

Fernando Cacho-Bailo, Carlos Téllez and Joaquín Coronas*

Page No. - Page No.

Interactive Thermal Effects on Metal-Organic Framework Polymer Composite Membranes 